\title{
Body fatness and breast cancer risk in women of African ancestry
}

\author{
Elisa V Bandera ${ }^{1,2^{*}}$, Urmila Chandran ${ }^{1,2}$, Gary Zirpoli ${ }^{3}$, Zhihong Gong ${ }^{3}$, Susan E McCann ${ }^{3}$, Chi-Chen Hong ${ }^{3}$,
} Gregory Ciupak ${ }^{3}$, Karen Pawlish ${ }^{4}$ and Christine B Ambrosone ${ }^{3}$

\begin{abstract}
Background: Obesity has been shown to be inversely associated with breast cancer risk in premenopausal women, while increasing risk in postmenopausal women. However, the current evidence is largely based on studies in Caucasian populations. Associations in women of African ancestry (AA), who have a higher prevalence of obesity, have been evaluated in few studies and results suggest different effects.

Methods: We evaluated the impact of body size, body fat distribution, and body composition on breast cancer risk among AA women (978 cases and 958 controls) participating in the Women's Circle of Health Study, a multi-site case-control study in New York City (NYC) and New Jersey (NJ). Cases were newly diagnosed with histologically confirmed ductal carcinoma in situ or invasive breast cancer, age 20-75 yrs. In NYC, cases were recruited through hospitals with the largest referral patterns for AA women and controls through random digit dialing (RDD). In NJ, cases were identified in seven counties in NJ thorough the NJ State Cancer Registry, and controls through RDD and community-based recruitment. During in-person interviews, questionnaires were administered and detailed anthropometric measurements were obtained. Body composition was assessed by bioelectrical impedance analysis.

Results: BMI did not have a major impact on pre- or post-menopausal breast cancer, but was significantly associated with reduced risk of ER-/PR- tumors among postmenopausal women (OR: 0.37; 95\% Cl: 0.15-0.96 for $\mathrm{BMI}>30$ vs. BMI < 25). Furthermore, increased premenopausal breast cancer risk was found for higher waist and hip circumferences after adjusting for BMI, with ORs of 2.25 ( $95 \% \mathrm{Cl}: 1.07-4.74)$ and 2.91 (95\% Cl: 1.39-6.10), respectively, comparing the highest vs. lowest quartile. While ORs for higher fat mass and percent body fat among postmenopausal women were above one, confidence intervals included the null value.

Conclusions: Our study suggests that in AA women BMI is generally unrelated to breast cancer. However, higher waist and hip circumferences were associated with increased pre-menopausal breast cancer risk, while general obesity was associated with decreased risk of ER-/PR- tumors. Larger studies are needed to confirm findings and to evaluate the impact of obesity on breast cancer subtypes.
\end{abstract}

Keywords: Breast cancer, Obesity, Body mass index, Body fat distribution, Waist circumference, Body composition, Percent body fat, African American

\footnotetext{
* Correspondence: elisa.bandera@rutgers.edu

${ }^{1}$ Rutgers Cancer Institute of New Jersey, Robert Wood Johnson Medical

School, 195 Little Albany Street, 08903 New Brunswick, NJ, USA

${ }^{2}$ Rutgers School of Public Health, Piscataway, NJ, USA

Full list of author information is available at the end of the article
} 


\section{Background}

In the United States, breast cancer is the most common cancer in women excluding skin cancer and the second leading cause of cancer mortality [1]. Rates vary considerably by race/ethnicity [1]. While women of African ancestry (AA) have lower incidence compared to those of European descent (EA), incidence is higher for those younger than 40 years [1]. AA women with breast cancer also experience the highest mortality rates for any racial/ethnic groups [1]. Several factors, many related to socio-economic status, have been proposed to explain these differences in AA women, including poorer access to screening, pre-existing conditions, suboptimal treatment for breast cancer, lifestyle factors, and obesity [2]. AA women tend to have aggressive tumor characteristics and more advanced tumors at diagnosis, which have also been linked to obesity $[3,4]$.

Obesity is a major public health concern in AA women, with the prevalence of obesity (BMI $\geq 30)$ being $58.6 \%$ for "non-Hispanic black women" and 33.4\% for "non-Hispanic white women", according to 2009-2010 National Health and Nutrition Examination Survey (NHANES) data [5]. AA women also tend to have higher waist circumference than EA women [4]. Excess body fatness is a well-recognized risk factor for breast cancer, with studies showing increased risk for postmenopausal women and an inverse association in pre-menopausal women [6]. However, there is growing evidence that this relationship is complex, with the association varying by race, age, HRT use, and possibly by hormone receptor status [7]. Furthermore, the current evidence is largely based on studies conducted in white women, with only a few studies evaluating the role of measures of body fatness, such as body mass, central adiposity, or percent body fat, among AA women [7,8]. The evidence from the few studies that evaluated the impact of BMI on breast cancer risk in AA women is generally inconsistent but suggests different effects (reviewed in $[3,7,8]$ ). Although some studies have indicated increased breast cancer risk associated with higher waist circumference and waist-to-hip ratio in pre-menopausal women [9], the overall evidence independent of BMI remains uncertain. The impact of body composition on breast cancer risk in AA women is unknown. Therefore, we evaluated the impact of body mass index, body fat distribution and body composition on breast cancer risk among preand postmenopausal AA women participating in the Women's Circle of Health Study.

\section{Methods}

\section{Study population}

The Women's Circle of Health Study (WCHS) is a multi-site case-control study in New York City (NYC) and New Jersey (NJ) specifically designed to evaluate genetic and lifestyle risk factors for early/aggressive breast cancer and to compare the distribution of these factors in AA and EA women. The study design has been described in detail elsewhere [10]. In brief, cases were self-identified AA and EA women, 20-75 years of age, and able to understand and read English with no previous history of cancer other than non-melanoma skin cancer, and diagnosed within 9 months with primary, histologically confirmed invasive breast cancer or ductal carcinoma in situ (DCIS). Controls had the same eligibility criteria and no history of cancer and were identified, recruited, and interviewed during the same time period as the cases.

In NYC, cases were identified through collaborations with hospitals in Manhattan, Bronx, Brooklyn, and Queens with the largest referral patterns for AA women. Controls in NYC were ascertained by RDD, using the telephone exchanges (area code plus three-digit prefixes) of breast cancer cases who received medical care at the participating hospitals in previous years for sampling, frequency matched by 5-year age groups and race. In New Jersey, cases were identified through the NJ State Cancer Registry (NJSCR), using rapid case ascertainment in seven counties (Bergen, Essex, Hudson, Mercer, Middlesex, Passaic, and Union), with extension Monmouth and Burlington counties in 2012. Controls were identified by RDD in NYC and NJ, frequency matched by age group and county of residence to the cases. In NJ, controls were also recruited through community sources, as described in detail elsewhere [11].

\section{Data collection}

After confirming eligibility, an in-person interview was scheduled at the participants' homes or a mutually agreed upon location. All interviewers underwent rigorous standardized training and testing before they were allowed to start conducting interviews and anthropometric measurements. Informed consent was obtained in person at the visit before data collection began. During the in-person interview several questionnaires were completed, body measurements taken, and biospecimens collected.

The WCHS survey instrument covered established and suspected risk factors for breast cancer, including family history, reproductive and menstrual history, hormone use, alcohol intake and smoking, occupational history, and physical activity. Women were also asked to report their weight and height one year before diagnosis (for cases) or reference date (for controls), and at several times during their life.

Anthropometric measurements were taken at the end of the visit using a standardized protocol based on the Women's Interview Study of Health [12] and measuring instruments. Participants were asked to wear light 
clothing and to remove their shoes and any heavy jewelry. Standing height was measured once to the nearest $0.1 \mathrm{~cm}$. Waist and hip circumferences were measured twice to the nearest $0.1 \mathrm{~cm}$ by placing the measuring tape around the waist covering the umbilicus (for waist) or at the maximum extension of the buttocks (for hip) in a horizontal plane. If the difference between the first and second measurement was greater than $2 \mathrm{~cm}$, a third measurement was taken. The two (or three) measurements were averaged for analyses. While there is no uniformly accepted protocol for measuring waist and hip circumference, repeated measurements have been shown to reduce measurement error and a clinically relevant change in waist circumference has been estimated to range between 3.0 and $6.8 \mathrm{~cm}$ [13]. Therefore, a tolerance limit of $2 \mathrm{~cm}$, below this clinically relevant range, was used. Body composition (lean and fat mass, percent body fat) was measured by bioelectrical impedance analysis using a Tanita ${ }^{\circ}$ TBF-300A scale. Weight was measured once using the Tanita scale.

A total of 979 AA cases and 958 AA controls completed the interview. Height and/or weight measurements were not available for 25 cases and 13 controls because the participants refused $(n=24)$, were more than 3 months pregnant $(n=2)$, or for other reasons (e.g., physical impairments) $(\mathrm{n}=12)$. Because we found high correlation between BMI based on measurements and based on self-reported weight and height $(r=0.92)$, missing values for height and/or weight were substituted with self-reported values when available to compute the final BMI variable used to compute risk estimates. One case was excluded because she did not have measured or self-reported weight and height, leaving 978 cases and 958 controls for analyses.

The study was approved by the Institutional Review Boards at the Cancer Institute of New Jersey (now Rutgers Cancer Institute of New Jersey), Mount Sinai School of Medicine (now the Icahn School of Medicine at Mount Sinai), and Roswell Park Cancer Institute and all participants provided written informed consent before participating in the study.

\section{Statistical analyses}

All analyses were conducted separately in pre- and postmenopausal women. BMI was computed as weight in kilograms $(\mathrm{kg})$ divided by the square of height in meters (m). Self-reported BMI one year prior to reference date (diagnosis date for cases and comparable date for controls) was calculated using measured height at interview and self-reported weight, except for 26 women for whom measured height was missing and instead, selfreported height was used. Fat mass index and fat free mass index were calculated as fat mass or fat free mass in $\mathrm{kg}$, respectively, divided by the square of height in meters. BMI was categorized according to the World Health Organization (WHO) International Classification. For all other variables we used quartiles, based on the distribution of all controls combined. We used the same cutpoints in the two subgroups by menopausal status to be able to compare risk estimates across categories.

Distributions of selected risk factors between cases and controls stratified by menopausal status were compared using chi-square tests and means compared using the $t$-test. Multivariable unconditional logistic regression was used to estimate odds ratios (OR) and 95\% confidence intervals $(\mathrm{CI})$, controlling for relevant confounders. Tests for trend were derived by assigning the median value to each category. Covariates considered included age, ethnicity (Hispanic vs. not Hispanic), country of origin (United States, Caribbean countries, other), education, family history of breast cancer, history of benign breast disease, age at menarche, age at menopause, parity, breastfeeding (never/ever), age at first birth, hormone replacement therapy use (never/ever), oral contraceptive use (never/ever), years since menopause (for analyses of body composition), and BMI in young adulthood. We also controlled for waist circumference when evaluating relationships with BMI, and BMI when evaluating relationships with body fat distribution to assess the potentially independent effects of general and central obesity, respectively.

Possible effect modification by hormone receptor status was evaluated by conducting stratified analyses according to the major subtypes (ER+/PR + and ER-/ PR-) in addition to conducting case-case analyses to estimate risk of ER-/PR- tumors compared to ER+/PR+ tumors. Analyses were repeated excluding HRT users and non-invasive tumors, as well as community controls. A finding with a $\mathrm{p}$ value of less than 0.05 was considered statistically significant. SAS version 9.2 (SAS Institute, Cary NC) was used for analyses.

\section{Results}

Selected characteristics for study participants by menopausal status are shown in Table 1 . For both pre- and post-menopausal women, cases tended to be slightly older and have fewer years of education than controls, while family history of breast cancer, history of benign breast disease, and use of HRT were more common in cases than controls in both pre- and post-menopausal women.

As shown in Table 2, there was little indication that BMI played a major role in breast cancer risk in AA women. ORs for both pre- and post-menopausal women with $\mathrm{BMI}>40$ were below one, but the confidence intervals included the null. We also evaluated BMI based on self-reported weight one year before reference date and measured height at interview, with no clear evidence of 
Table 1 Selected characteristics among women of African ancestry in the Women's Circle of Health Study

\begin{tabular}{|c|c|c|c|c|c|c|}
\hline & \multicolumn{3}{|c|}{ Pre-menopausal } & \multicolumn{3}{|c|}{ Post-menopausal } \\
\hline & $\begin{array}{c}\text { Cases } \\
(\mathrm{n}=469) \\
\mathrm{n}(\%)\end{array}$ & $\begin{array}{l}\text { Controls } \\
\begin{array}{c}(n=482) \\
n(\%)\end{array}\end{array}$ & $p$ value & $\begin{array}{c}\text { Cases } \\
(\mathrm{n}=509) \\
\mathrm{n}(\%)\end{array}$ & $\begin{array}{c}\text { Controls } \\
\text { (n= 476) } \\
n(\%)\end{array}$ & $p$ value \\
\hline \multicolumn{7}{|l|}{ Age (yrs) } \\
\hline Mean \pm SD & $43.93 \pm 6.8$ & $42.65 \pm 7.1$ & 0.005 & $59.68 \pm 6.7$ & $57.70 \pm 6.1$ & $<0.0001$ \\
\hline \multicolumn{7}{|l|}{ Education } \\
\hline$<$ High school & $57(12.2)$ & $67(13.9)$ & 0.07 & $90(17.7)$ & $57(12)$ & 0.003 \\
\hline High school graduate & $133(28.4)$ & $112(23.2)$ & & $165(32.4)$ & $130(27.3)$ & \\
\hline Some college & $136(29)$ & $120(24.9)$ & & $122(24)$ & $159(33.4)$ & \\
\hline College graduate & $91(19.4)$ & $121(25.1)$ & & $81(15.9)$ & 74 (15.6) & \\
\hline Post-graduate degree & $52(11.1)$ & $62(12.9)$ & & $51(10)$ & $56(11.8)$ & \\
\hline \multicolumn{7}{|l|}{ Marital Status } \\
\hline Married & $184(39.2)$ & $176(36.5)$ & 0.05 & $158(31.1)$ & $155(32.7)$ & 0.19 \\
\hline Living as married & $8(1.7)$ & $9(1.9)$ & & $6(1.2)$ & $11(2.3)$ & \\
\hline Widowed & $10(2.1)$ & $14(2.9)$ & & $88(17.3)$ & $57(12)$ & \\
\hline Separated & $35(7.5)$ & $22(4.6)$ & & $38(7.5)$ & $38(8)$ & \\
\hline Divorced & $71(15.1)$ & $55(11.4)$ & & $102(20.1)$ & 93 (19.6) & \\
\hline Single & $161(34.3)$ & $206(42.7)$ & & $116(22.8)$ & $120(25.3)$ & \\
\hline \multicolumn{7}{|l|}{ Country of origin } \\
\hline United States & $297(63.3)$ & $378(78.4)$ & $<0.0001$ & $404(79.4)$ & $391(82.1)$ & 0.54 \\
\hline Caribbean & $131(27.9)$ & 75 (15.6) & & $74(14.5)$ & $61(12.8)$ & \\
\hline Other & $41(8.7)$ & $29(6)$ & & $31(6.1)$ & $24(5)$ & \\
\hline \multicolumn{7}{|l|}{ Ethnicity } \\
\hline Hispanic & $29(6.2)$ & $14(2.9)$ & 0.02 & $16(3.1)$ & $12(2.5)$ & 0.56 \\
\hline Non-Hispanic & $440(93.8)$ & $468(97.1)$ & & $493(96.9)$ & $464(97.5)$ & \\
\hline \multicolumn{7}{|l|}{ Age at menarche (yrs) } \\
\hline$<12$ & $139(29.6)$ & $144(29.9)$ & 0.52 & $152(29.9)$ & $121(25.5)$ & 0.23 \\
\hline $12-13$ & $220(46.9)$ & $211(43.8)$ & & $221(43.4)$ & $229(48.2)$ & \\
\hline$>13$ & $110(23.5)$ & $127(26.4)$ & & $136(26.7)$ & $125(26.3)$ & \\
\hline \multicolumn{7}{|l|}{ Age at menopause (yrs) } \\
\hline$\leq 45$ & & & & $70(14.1)$ & $78(16.5)$ & $<0.001$ \\
\hline $46-49$ & & & & $64(12.9)$ & $107(22.7)$ & \\
\hline $50-54$ & & & & $311(62.5)$ & $242(51.3)$ & \\
\hline$\geq 55$ & & & & $53(10.6)$ & $45(9.5)$ & \\
\hline \multicolumn{7}{|l|}{ Parity (livebirths) } \\
\hline 0 & 87 (18.6) & $82(17)$ & 0.17 & $67(13.2)$ & $75(15.8)$ & 0.17 \\
\hline $1-2$ & $257(54.8)$ & $241(50)$ & & $242(47.5)$ & $235(49.4)$ & \\
\hline $3-4$ & $104(22.2)$ & $127(26.4)$ & & $137(26.9)$ & $126(26.5)$ & \\
\hline$\geq 5$ & $21(4.5)$ & $32(6.6)$ & & $63(12.4)$ & $40(8.4)$ & \\
\hline \multicolumn{7}{|l|}{ Age at first birth (yrs) } \\
\hline Nulliparous & 87 (18.6) & $82(17)$ & 0.32 & $67(13.2)$ & 75 (15.8) & 0.41 \\
\hline$\leq 19$ & $127(27.1)$ & $148(30.7)$ & & $190(37.3)$ & $168(35.4)$ & \\
\hline $20-24$ & $108(23.1)$ & $117(24.3)$ & & $131(25.7)$ & $120(25.3)$ & \\
\hline
\end{tabular}


Table 1 Selected characteristics among women of African ancestry in the Women's Circle of Health Study (Continued)

\begin{tabular}{|c|c|c|c|c|c|c|}
\hline $25-30$ & 89 (19) & $70(14.5)$ & & $82(16.1)$ & $64(13.5)$ & \\
\hline$\geq 31$ & $57(12.2)$ & $65(13.5)$ & & $39(7.7)$ & $47(9.9)$ & \\
\hline \multicolumn{7}{|l|}{ Breastfeeding } \\
\hline Nulliparous & $87(18.6)$ & $82(17)$ & 0.32 & $67(13.2)$ & $75(15.8)$ & 0.34 \\
\hline Never (among parous) & $158(33.7)$ & $185(38.4)$ & & $267(52.5)$ & $230(48.3)$ & \\
\hline Ever & $224(47.8)$ & $215(44.6)$ & & $175(34.4)$ & $171(35.9)$ & \\
\hline \multicolumn{7}{|l|}{ Family history } \\
\hline No & $370(78.9)$ & $416(86.3)$ & 0.003 & $365(71.7)$ & $389(81.7)$ & $<0.001$ \\
\hline Yes & $99(21.1)$ & $66(13.7)$ & & $144(28.3)$ & $87(18.3)$ & \\
\hline \multicolumn{7}{|c|}{ History of benign breast disease } \\
\hline Never & $333(71.3)$ & $393(81.7)$ & $<0.001$ & $330(64.8)$ & $345(72.5)$ & 0.01 \\
\hline Ever & $134(28.7)$ & $88(18.3)$ & & $179(35.2)$ & $131(27.5)$ & \\
\hline \multicolumn{7}{|l|}{ HRT use } \\
\hline Never & $449(96.2)$ & $467(96.9)$ & 0.53 & $375(74.4)$ & $378(79.8)$ & 0.05 \\
\hline Ever & $18(3.9)$ & $15(3.1)$ & & $129(25.6)$ & $96(20.3)$ & \\
\hline \multicolumn{7}{|l|}{ Oral contraceptive use } \\
\hline Never & $175(37.3)$ & $189(39.2)$ & 0.55 & $212(41.7)$ & $220(46.4)$ & 0.14 \\
\hline Ever & $294(62.7)$ & $293(60.8)$ & & $296(58.3)$ & $254(53.6)$ & \\
\hline \multicolumn{7}{|l|}{ Smoking status } \\
\hline Never smoker & $297(71.4)$ & $287(60.7)$ & $<0.001$ & $219(53.4)$ & $226(52.3)$ & 0.13 \\
\hline Former smoker & $62(14.9)$ & $76(16.1)$ & & $127(31)$ & $117(27.1)$ & \\
\hline Current smoker & 57 (13.7) & $110(23.3)$ & & 64 (15.6) & 89 (20.6) & \\
\hline
\end{tabular}

SD standard deviation.

a dose-response association either. Results were similar after adjusting for waist circumference (Table 2).

When we evaluated measures of body fat distribution in pre- and post-menopausal women (Table 3), there was a weak positive association for postmenopausal women with higher waist-to-hip ratio (WHR) but the confidence intervals included the null value (OR: 1.43; 95\% CI: 0.95-2.18 comparing highest to lowest quartile). However, after adjusting for BMI, a strong association emerged with waist and hip circumferences for premenopausal women, with an OR for waist circumference of 2.25 (95\% CI: 1.07-4.74) for the highest vs. lowest quartile and an estimated 10\% increase in risk per $5 \mathrm{~cm}$ increment in waist circumference. For hip circumference, after adjusting for BMI, the OR for the highest vs. lowest quartile was 2.91 (95\% CI: 1.39-6.10), with a $12 \%$ increase in risk per $5 \mathrm{~cm}$ increment in hip circumference. Among post-menopausal women, no clear associations were observed. No association was also found for pre- or postmenopausal women with any of the body composition measures considered: fat mass, fat free mass, percent body fat, fat mass index, and fat free mass index (Table 4).

Restricting analyses to invasive cases led to essentially the same results (data not shown). Because it has been suggested that the relationship between BMI and breast cancer risk may be limited to non-HRT users $[14,15]$, we also repeated analyses excluding HRT users (Table 5). Among non-HRT users, while there was no association with BMI, other adiposity measures tended to increase risk but most estimates were not significant, with the exception of hip circumference among pre-menopausal women, which significantly increased breast cancer risk. Excluding community controls did not substantially change estimates.

We also explored possible effect modification by the major breast cancer subtypes based on hormone receptor status: ER+/PR+ and ER-/PR- (Tables 6 and 7). The major findings were a strong association with hip circumference for $\mathrm{ER}+/ \mathrm{PR}+$ tumors for pre-menopausal women and an inverse association with BMI for ER-/PRtumors for post-menopausal women. No other clear patterns emerged from these analyses.

\section{Discussion}

In this study we found that BMI did not play a major role on breast cancer among AA women, except for a significant inverse association for ER-/PR- tumors in post-menopausal women. Furthermore, higher waist and hip circumferences increased pre-menopausal breast 
Table 2 Association of body size and breast cancer risk in women of African ancestry, Women's Circle of Health Study

\begin{tabular}{|c|c|c|c|c|c|c|c|c|c|c|}
\hline & \multicolumn{5}{|c|}{ Pre-menopausal } & \multicolumn{5}{|c|}{ Post-menopausal } \\
\hline & Cases/Controls & OR1 & $95 \% \mathrm{Cl}$ & OR2 & $95 \% \mathrm{Cl}$ & Cases/Controls & OR1 & $95 \% \mathrm{Cl}$ & OR2 & $95 \% \mathrm{Cl}$ \\
\hline \multicolumn{11}{|l|}{ Current BMI* } \\
\hline Underweight/Normal $(<25)$ & $102 / 103$ & Ref & & Ref & & $74 / 68$ & Ref & & Ref & \\
\hline Overweight (25-29.99) & $150 / 142$ & 1.02 & $0.70-1.49$ & 1.05 & $0.70-1.57$ & $131 / 132$ & 0.93 & $0.60-1.44$ & 0.93 & $0.59-1.47$ \\
\hline Obese $(\geq 30)$ & $217 / 237$ & 0.89 & $0.61-1.28$ & 0.92 & $0.54-1.56$ & $304 / 276$ & 0.98 & $0.66-1.45$ & 1.00 & $0.58-1.72$ \\
\hline$p$ for trend & & & 0.40 & & 0.65 & & & 0.94 & & 0.86 \\
\hline \multicolumn{11}{|l|}{ Current BMI* } \\
\hline Underweight/Normal $(<25)$ & $102 / 103$ & Ref & & Ref & & $74 / 68$ & Ref & & Ref & \\
\hline Pre-obese (25-29.99) & $150 / 142$ & 1.01 & $0.69-1.48$ & 0.98 & $0.64-1.49$ & $131 / 132$ & 0.93 & $0.60-1.44$ & 0.88 & $0.55-1.41$ \\
\hline Obese Class I (30-34.99) & $111 / 94$ & 1.06 & $0.70-1.61$ & 0.93 & $0.54-1.62$ & $146 / 121$ & 1.08 & $0.70-1.68$ & 0.98 & $0.56-1.72$ \\
\hline Obese Class II (35-39.99) & $50 / 68$ & 0.71 & $0.43-1.17$ & 0.62 & $0.31-1.26$ & $94 / 89$ & 0.90 & $0.56-1.44$ & 0.80 & $0.41-1.58$ \\
\hline Obese Class III ( $\geq 40)$ & $56 / 75$ & 0.79 & $0.49-1.29$ & 0.64 & $0.26-1.56$ & $64 / 66$ & 0.89 & $0.53-1.48$ & 0.74 & $0.31-1.78$ \\
\hline $\mathrm{p}$ for trend & & & 0.17 & & 0.20 & & & 0.65 & & 0.47 \\
\hline \multicolumn{11}{|c|}{ BMI one year before reference date $e^{* *}$} \\
\hline Underweight/Normal $(<25)$ & $115 / 113$ & Ref & & Ref & & $66 / 77$ & Ref & & Ref & \\
\hline Overweight (25-29.99) & $138 / 143$ & 0.86 & $0.59-1.25$ & 0.90 & $0.61-1.33$ & $147 / 140$ & 1.27 & $0.82-1.96$ & 1.32 & $0.84-2.07$ \\
\hline Obese $(\geq 30)$ & $214 / 221$ & 0.91 & $0.63-1.30$ & 1.00 & $0.62-1.62$ & $293 / 254$ & 1.27 & $0.85-1.89$ & 1.46 & $0.87-2.44$ \\
\hline$p$ for trend & & & 0.74 & & 0.88 & & & 0.41 & & 0.22 \\
\hline \multicolumn{11}{|c|}{ BMI one year before reference date ${ }^{* *}$} \\
\hline Underweight/Normal $(<25)$ & $115 / 113$ & Ref & & Ref & & $66 / 77$ & Ref & & Ref & \\
\hline Pre-obese (25-29.99) & $138 / 143$ & 0.86 & $0.59-1.25$ & 0.87 & $0.58-1.29$ & $147 / 140$ & 1.27 & $0.82-1.96$ & 1.32 & $0.83-2.08$ \\
\hline Obese Class I (30-34.99) & $121 / 92$ & 1.17 & $0.77-1.76$ & 1.16 & $0.71-1.90$ & $143 / 129$ & 1.23 & $0.79-1.90$ & 1.34 & $0.80-2.27$ \\
\hline Obese Class II (35-39.99) & $43 / 73$ & 0.55 & $0.33-0.90$ & 0.54 & $0.28-1.02$ & $87 / 55$ & 1.70 & $1.02-2.82$ & 1.97 & $1.02-3.82$ \\
\hline Obese Class III ( $\geq 40)$ & $50 / 56$ & 0.93 & $0.56-1.54$ & 0.93 & $0.43-2.00$ & $63 / 70$ & 0.98 & $0.58-1.64$ & 1.19 & $0.55-2.55$ \\
\hline$p$ for trend & & & 0.39 & & 0.61 & & & 0.86 & & 0.64 \\
\hline
\end{tabular}

*BMI measured at interview. **Based on self-reported weight one year before reference date and measured height at interview.

OR1: Adjusted for age, ethnicity, country of origin (United States, Caribbean, other), education, family history of breast cancer, history of benign breast disease, age at menarche, age at menopause (for postmenopausal women), parity (continuous), breastfeeding (yes/no), age at first birth, HRT use (ever/never), OC use (ever/never). OR2: Further adjusted for waist circumference.

cancer risk, independent of BMI. While there was a suggestion of increased risk with higher fat mass and percent body fat among post-menopausal women, confidence intervals included the null value.

Very few studies have previously evaluated the role of recent $\mathrm{BMI}$ on breast cancer risk among AA (reviewed in $[3,7,8]$ ) and in general, previous findings are in agreement with ours. As in our study, no association with pre-menopausal breast cancer was reported in six other case-control studies [16-21] and one cohort study [22]. For post-menopausal breast cancer, results have been inconsistent. Similar to our results, no increased risk was reported in most of these studies, with an inverse association suggested in four of the case-control studies $[16,18,23,24]$, weak and non-significant association in another case-control study [21] and in the Multi-Ethnic Cohort [25], and no association in the Black Women's Health Study cohort [22]. Only two case-control studies have reported an increased risk among AA women
$[17,19]$. Two additional studies conducted in Nigeria [26] and Barbados [27] reported no association with BMI. One of the most striking results from our study is the strong inverse association with BMI for ER-/PRtumors among post-menopausal women. Similar inverse association was suggested in the two studies that presented stratified analyses by receptor status, the Women's CARE Study [21] and in the Black Women's Health Study [22]. However, confidence intervals in these two studies included the null, and, therefore, more studies are needed to understand the role of BMI on ER-/PR- tumors and on postmenopausal breast cancer in general.

In contrast to the findings for general obesity, we found a strong association with waist and hip circumferences, after adjusting for BMI in pre-menopausal women. While studies have typically used WHR to measure body fat distribution, waist circumference has been shown to be a better marker of central obesity than WHR in AA women [4]. Other studies, largely conducted among EA women, 
Table 3 Body fat distribution measures and breast cancer risk

\begin{tabular}{|c|c|c|c|c|c|c|c|c|c|c|}
\hline & \multicolumn{5}{|c|}{ Pre-menopausal } & \multicolumn{5}{|c|}{ Post-menopausal } \\
\hline & Cases/Controls & OR1 & $95 \% \mathrm{Cl}$ & OR2 & $95 \% \mathrm{Cl}$ & Cases/Controls & OR1 & $95 \% \mathrm{Cl}$ & OR2 & $95 \% \mathrm{Cl}$ \\
\hline \multicolumn{11}{|l|}{ Waist to hip ratio } \\
\hline$\leq 0.82$ & $123 / 144$ & Ref & & Ref & & $65 / 93$ & Ref & & Ref & \\
\hline $0.83-0.87$ & $128 / 120$ & 1.14 & $0.79-1.65$ & 1.20 & $0.82-1.74$ & $146 / 117$ & 1.58 & $1.03-2.40$ & 1.59 & $1.04-2.42$ \\
\hline $0.88-0.92$ & $105 / 121$ & 0.98 & $0.66-1.44$ & 1.07 & $0.72-1.60$ & $120 / 116$ & 1.22 & $0.79-1.88$ & 1.24 & $0.80-1.92$ \\
\hline$>0.92$ & $104 / 93$ & 1.19 & $0.80-1.79$ & 1.38 & $0.89-2.12$ & $169 / 144$ & 1.43 & $0.95-2.18$ & 1.48 & $0.97-2.26$ \\
\hline $\mathrm{p}$ for trend & & & 0.55 & & 0.22 & & & 0.33 & & 0.27 \\
\hline \multicolumn{11}{|c|}{ Waist circumference $(\mathrm{cm})$} \\
\hline$\leq 87.88$ & $137 / 143$ & Ref & & Ref & & $87 / 94$ & Ref & & Ref & \\
\hline 87.89-97.75 & $124 / 119$ & 1.02 & $0.70-1.46$ & 1.26 & $0.85-1.88$ & 119/118 & 1.07 & $0.71-1.61$ & 1.13 & $0.73-1.76$ \\
\hline $97.76-110.25$ & $107 / 116$ & 0.93 & $0.64-1.37$ & 1.47 & $0.88-2.44$ & $154 / 121$ & 1.35 & $0.90-2.02$ & 1.51 & $0.92-2.48$ \\
\hline$>110.25$ & $92 / 100$ & 0.98 & $0.65-1.48$ & 2.25 & $1.07-4.74$ & $140 / 137$ & 1.00 & $0.67-1.50$ & 1.23 & $0.64-2.34$ \\
\hline $\mathrm{p}$ for trend & & & 0.84 & & 0.04 & & & 0.96 & & 0.48 \\
\hline Per $5 \mathrm{~cm}$ & & 0.99 & $0.95-1.03$ & 1.10 & $1.00-1.22$ & & 1.00 & $0.96-1.04$ & 1.03 & $0.94-1.13$ \\
\hline \multicolumn{11}{|c|}{ Hip circumference $(\mathrm{cm})$} \\
\hline$\leq 103.18$ & $127 / 138$ & Ref & & Ref & & $107 / 99$ & Ref & & Ref & \\
\hline $103.19-111.63$ & 133/111 & 1.25 & $0.86-1.81$ & 1.60 & $1.07-2.39$ & $129 / 126$ & 0.99 & $0.67-1.47$ & 0.99 & $0.65-1.51$ \\
\hline $111.64-123.15$ & $101 / 116$ & 1.00 & $0.68-1.46$ & 1.60 & $0.98-2.60$ & $145 / 122$ & 1.16 & $0.79-1.72$ & 1.16 & $0.71-1.89$ \\
\hline$>123.15$ & 100/113 & 1.07 & $0.72-1.59$ & 2.91 & $1.39-6.10$ & $119 / 123$ & 0.88 & $0.59-1.31$ & 0.87 & $0.45-1.71$ \\
\hline $\mathrm{p}$ for trend & & & 0.99 & & 0.01 & & & 0.54 & & 0.69 \\
\hline Per $5 \mathrm{~cm}$ & & 0.98 & $0.93-1.03$ & 1.12 & $0.99-1.27$ & & 0.98 & $0.94-1.03$ & 0.97 & $0.87-1.08$ \\
\hline
\end{tabular}

OR1: Adjusted for age, ethnicity, country of origin (United States, Caribbean, other), education, family history of breast cancer, history of benign breast disease, age at menarche, age at menopause (for postmenopausal women), parity (continuous), breastfeeding (yes/no), age at first birth, HRT use (ever/never), OC use (ever/never). OR2: Further adjusted for BMI

have generally reported increased risk of postmenopausal breast cancer associated with central adiposity, mostly measured with WHR [4], although there is some inconsistency across studies particularly for WHR [6] and no association for premenopausal breast cancer [4]. However, a recent meta-analysis reported that after adjusting for BMI, the association with WHR for postmenopausal breast cancer disappeared, while introducing an association for pre-menopausal breast cancer [9]. To our knowledge, only the Carolina Breast Cancer Study (CBCS) [18], the Black Women's Health Study (BWHS) [22], the San Francisco Bay Area Breast Cancer Study (in pre-menopausal women) [20], and the Nigeria Breast Cancer Study (NBCS) [28] have reported on the association in AA women. For pre-menopausal breast cancer, two of the case-control studies (CBCS and NBCS) $[18,28]$ found elevated risk with higher WHR $[18,28]$ and waist circumference adjusted for BMI [28]. However, in contrast to our findings, an inverse association with hip circumference adjusted for BMI was found in the NBCS [28]. No association with WHR or waist circumference was found in the Bay Area case-control study [20] or the BWHS [22].

For post-menopausal breast cancer, the two case-control studies $[18,28]$ suggested increased risk with central obesity. In CBCS [18], there was a suggestion of increased risk with higher WHR after adjusting for BMI but the confidence interval include the null, similar to our findings. The NBCS [28] found increased risk for high waist circumference and WHR independent of BMI, and an inverse association with hip circumference, which is in the same direction as our results. There was little evidence of an association with self-reported waist circumference or WHR in the BWHS [22].

To examine breast cancer relationships with obesity and central adiposity independently, our analytic strategy involved generating mutually adjusted risk estimates. Because measures of central obesity (e.g., waist circumference) and BMI in general tend to be correlated, however, there is potential for multicollinearity and inadvertent introduction of bias [29]. To ensure that this is not a concern, we carried out additional analyses to examine the impact of assessing BMI simultaneously with waist circumference, and determine whether issues with multicollinearity were impacting our risk estimates. Since the outcome is binary, the options for testing multicollinearity such as variance inflation factor (VIF) and tolerance, which are applied to continuous outcomes, do not directly apply. However, a general recommendation to check 
Table 4 Body composition measures and breast cancer

\begin{tabular}{|c|c|c|c|c|c|c|c|c|c|c|}
\hline & \multicolumn{5}{|c|}{ Pre-menopausal } & \multicolumn{5}{|c|}{ Post-menopausal } \\
\hline & Cases/Controls & OR1 & $95 \% \mathrm{Cl}$ & OR2 & $95 \% \mathrm{Cl}$ & Cases/Controls & OR1 & $95 \% \mathrm{Cl}$ & OR2 & $95 \% \mathrm{Cl}$ \\
\hline \multicolumn{11}{|l|}{ Fat mass $(\mathrm{kg})$} \\
\hline$\leq 25.3$ & $128 / 125$ & Ref & & Ref & & $101 / 102$ & Ref & & Ref & \\
\hline $25.4-34.1$ & $131 / 116$ & 1.08 & $0.74-1.56$ & 1.24 & $0.82-1.87$ & $126 / 107$ & 1.16 & $0.78-1.74$ & 1.34 & $0.86-2.07$ \\
\hline $34.2-44.3$ & $96 / 100$ & 0.92 & $0.62-1.37$ & 1.19 & $0.70-2.03$ & $124 / 123$ & 0.94 & $0.63-1.40$ & 1.21 & $0.72-2.04$ \\
\hline$>44.3$ & $87 / 114$ & 0.82 & $0.54-1.23$ & 1.39 & $0.61-3.14$ & $120 / 110$ & 1.05 & $0.70-1.57$ & 1.69 & $0.82-3.49$ \\
\hline$p$ for trend & & & 0.24 & & 0.49 & & & 0.93 & & 0.22 \\
\hline \multicolumn{11}{|l|}{ Fat free mass $(\mathrm{kg})$} \\
\hline$\leq 44.1$ & $112 / 108$ & Ref & & Ref & & $130 / 118$ & Ref & & Ref & \\
\hline $44.2-48$ & $121 / 125$ & 0.94 & $0.64-1.39$ & 1.04 & $0.70-1.55$ & $134 / 99$ & 1.28 & $0.87-1.88$ & 1.32 & $0.88-1.96$ \\
\hline $48.1-52.6$ & 106/99 & 1.00 & $0.67-1.51$ & 1.24 & $0.78-1.98$ & $107 / 124$ & 0.87 & $0.59-1.27$ & 0.92 & $0.59-1.43$ \\
\hline$>52.6$ & $103 / 123$ & 0.84 & $0.57-1.26$ & 1.32 & $0.70-2.47$ & 101/101 & 0.96 & $0.65-1.43$ & 1.05 & $0.61-1.83$ \\
\hline$p$ for trend & & & 0.44 & & 0.35 & & & 0.47 & & 0.88 \\
\hline \multicolumn{11}{|l|}{ Percent body fat } \\
\hline$\leq 35.9$ & 145/137 & Ref & & Ref & & $93 / 94$ & Ref & & Ref & \\
\hline $36-41.6$ & $118 / 118$ & 0.92 & $0.64-1.33$ & 1.02 & $0.69-1.52$ & 123/107 & 1.14 & $0.75-1.71$ & 1.27 & $0.83-1.96$ \\
\hline $41.7-46.5$ & $96 / 104$ & 0.88 & $0.60-1.30$ & 1.07 & $0.67-1.72$ & $119 / 124$ & 0.85 & $0.57-1.29$ & 1.05 & $0.65-1.70$ \\
\hline$>46.5$ & $83 / 106$ & 0.82 & $0.55-1.23$ & 1.22 & $0.62-2.42$ & $137 / 119$ & 1.09 & $0.73-1.63$ & 1.59 & $0.87-2.93$ \\
\hline$p$ for trend & & & 0.32 & & 0.65 & & & 0.98 & & 0.26 \\
\hline \multicolumn{11}{|l|}{ Fat mass index } \\
\hline$\leq 9.37$ & $128 / 129$ & Ref & & - & - & $86 / 96$ & Ref & & - & - \\
\hline $9.38-12.78$ & 138/119 & 1.09 & $0.75-1.58$ & - & - & $124 / 104$ & 1.39 & $0.92-2.11$ & - & - \\
\hline $12.79-16.77$ & $93 / 98$ & 0.95 & $0.63-1.42$ & - & - & $140 / 127$ & 1.13 & $0.75-1.70$ & - & - \\
\hline$>16.77$ & $83 / 109$ & 0.80 & $0.53-1.21$ & - & - & $121 / 115$ & 1.10 & $0.72-1.66$ & - & - \\
\hline$p$ for trend & & & 0.35 & - & - & & & 0.58 & - & - \\
\hline Fat free mass index & & & & - & - & & & & - & - \\
\hline$\leq 16.64$ & $126 / 118$ & Ref & & - & - & $123 / 106$ & Ref & & - & - \\
\hline $16.65-18.04$ & $116 / 121$ & 0.88 & $0.60-1.28$ & - & - & $108 / 104$ & 0.94 & $0.63-1.40$ & - & - \\
\hline 18.05-19.80 & 99/99 & 0.85 & $0.57-1.28$ & - & - & $129 / 124$ & 0.89 & $0.60-1.30$ & - & - \\
\hline$>19.80$ & 101/117 & 0.81 & $0.54-1.21$ & - & - & $112 / 108$ & 0.86 & $0.58-1.28$ & - & - \\
\hline$p$ for trend & & & 0.33 & - & - & & & 0.45 & - & - \\
\hline
\end{tabular}

Fat mass index: fat mass in kg/(height in $\mathrm{m}^{2}{ }^{2}$; Fat Free Mass index: fat free mass in kg/(height in m) ${ }^{2}$ OR1: Adjusted for age, ethnicity, country of origin, education, family history of breast cancer, history of benign breast disease, age at menarche, years since menopause (for postmenopausal women), parity (continuous), breastfeeding (yes/no), age at first birth, HRT use (never/ever), OC use (never/ever). OR2: Further adjusted for BMI.

multicollinearity in logistic models is to run a similar model in linear regression and obtain collinearity statistics [30]. When we obtained tolerance and VIF statistics using this approach, the VIFs for BMI and waist circumference were over 4 , indicating that the respective standard errors of these variables are twice as inflated relative to the absence of multicollinearity. However, when we checked the standard errors of these two variables in the logistic model, they were 0.01 for waist circumference and 0.02 for BMI, indicating that there was no substantial inflation, and suggesting that multicollinearity, if any, was not a severe issue in this model.
Another sign of multicollinearity is if the global model is significant but none of the individual covariates are significant. In our model that included waist circumference and BMI, the coefficients of both variables were statistically significant $(\mathrm{p} \leq 0.05)$. Lastly, we obtained significant associations both when waist circumference was treated in linear and non-linear forms. Put together, these results point to an issue of confounding rather than moderate or severe multicollinearity. In general, when waist circumference is included in the model as independent variables with BMI as a covariate, BMI becomes more of an index of lean mass than fatness in this multivariate model 
Table 5 Association of body size and breast cancer risk among non-HRT users (excluding $\mathbf{n}=\mathbf{2 6 7}$ HRT users)

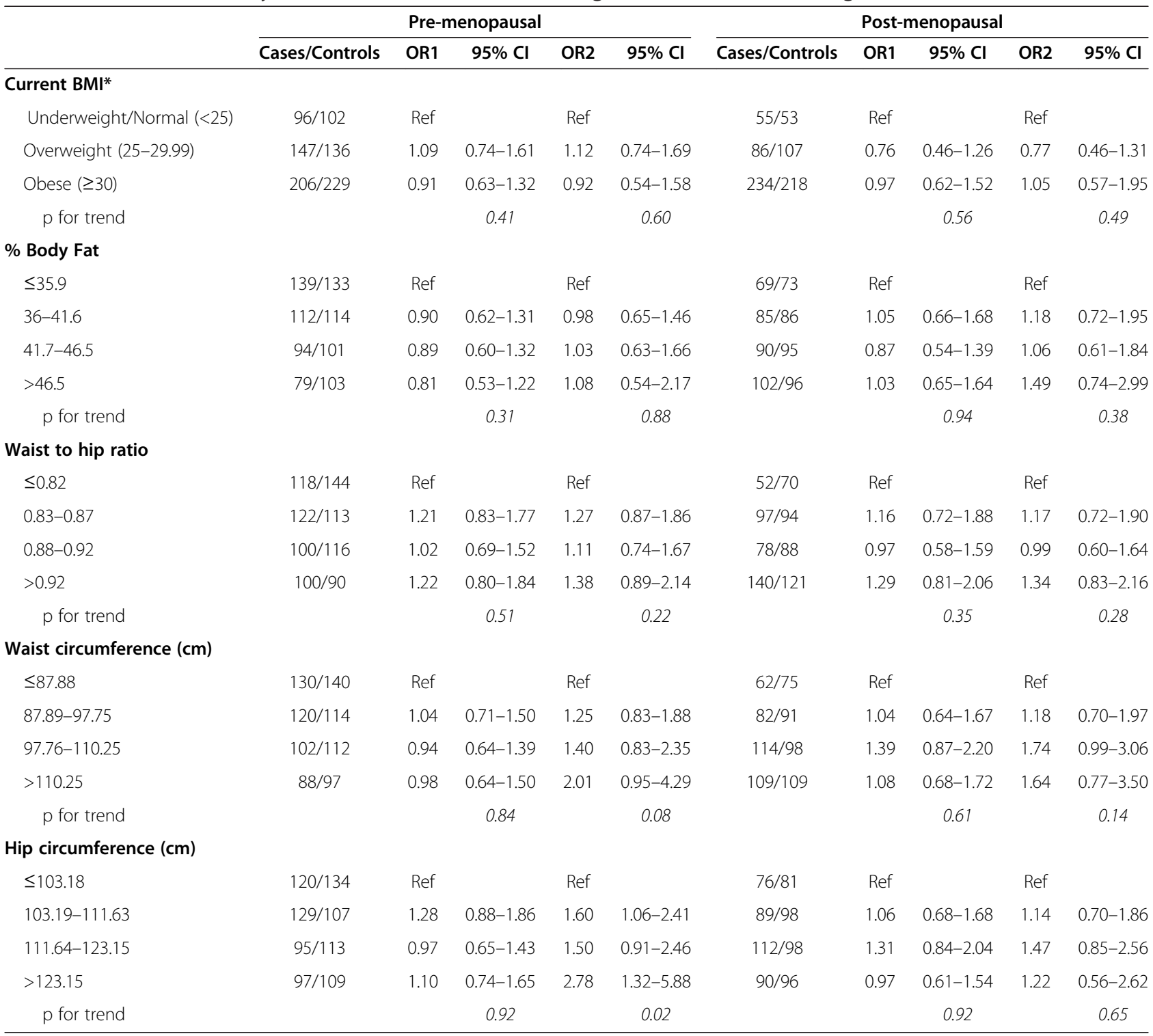

*BMI measured at interview.

OR1: Adjusted for age, ethnicity, country of origin (United States, Caribbean, other), education, family history of breast cancer, history of benign breast disease, age at menarche, age at menopause (for postmenopausal women), parity (continuous), breastfeeding (yes/no), age at first birth, OC use (ever/never). OR2: BMI further adjusted for waist circumference. Percent body fat, waist circumference and hip circumference, further adjusted for BMI. Percent body fat adjusted for years since menopause instead of age at menopause.

because the component of weight due to fatness is accounted for by abdominal circumference [31]. Therefore, the evaluation of waist circumference adjusted for BMI may be a better assessment of the association with adiposity. Given this, it makes sense that the effect of adjusting for BMI was more pronounced in premenopausal women, who tend to have more lean mass.

The role of body composition on breast cancer risk has received little attention, particularly among AA women and, to our knowledge, we are the first study to evaluate it and found no significant associations. It should be noted that we used bioelectrical impedance to measure body composition, which is not as precise as other methods, such as dual energy $\mathrm{x}$-ray absorptiometry (DXA) and computed axial tomography (CAT) [32]. Therefore, our methods may have led to some degree of random misclassification in body composition measures that may have hampered our ability to detect an association. We are also aware that breast cancer treatment and menopause may affect body composition [32]. Increases in body fat and decreases in lean body mass after breast cancer treatment have been reported in studies, but not consistently, and these changes are not easily separated from those occurring with the aging process 
Table 6 Association of body size with premenopausal breast cancer by hormone receptor status

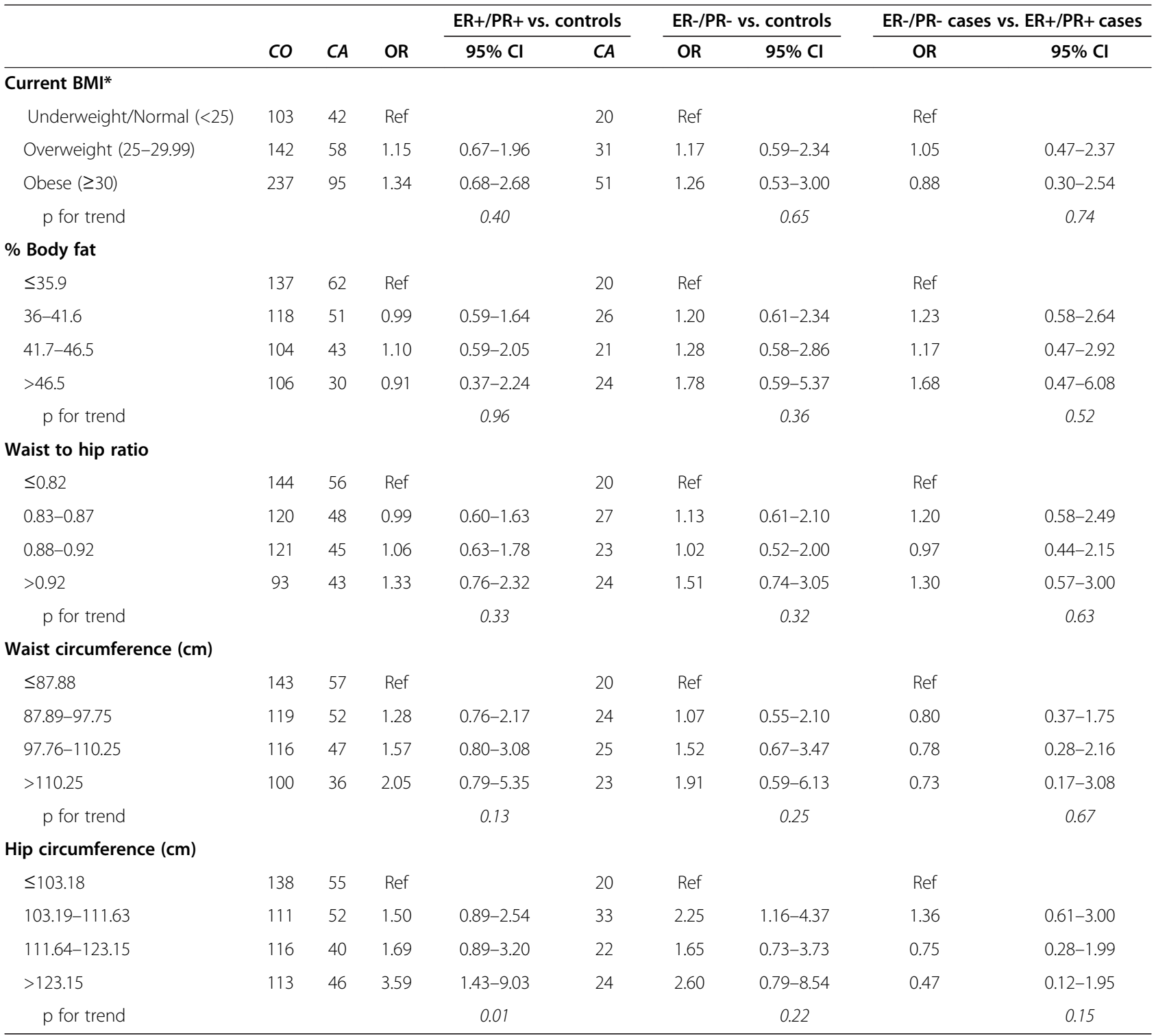

*BMI measured at interview.

Abbreviations: CO number of controls, CA number of cases, ER estrogen receptor, PR progesterone receptor.

Adjusted for age, ethnicity, country of origin (United States, Caribbean, other), education, family history of breast cancer, history of benign breast disease, age at menarche, parity (continuous), breastfeeding (yes/no), age at first birth, HRT use (ever/never), OC use (ever/never). BMI also adjusted for waist circumference. Percent body fat, waist circumference, and hip circumference, also adjusted for BMI.

[32]. For example, it is not certain whether these changes in adiposity found in some studies could be attributed to chemotherapy, or could be due to ovarian failure caused by chemotherapy in premenopausal women [32] or to behavioral changes after breast cancer diagnosis. We adjusted analyses of body composition for age and years since menopause, but were not able to adjust for years since ovarian failure in pre-menopausal women.

Our findings generally confirm the small but growing body of literature suggesting that obesity may have a different impact on AA compared to EA women. The association of BMI with body fatness varies by age, gender, and race/ethnicity [33]. Body weight and BMI measures may not capture variations of fat mass and lean mass among women. In fact, for a given BMI, AA women tend to have higher lean mass and lower fat than white women [33]. Therefore, for AA women, waist and hip circumferences and percent body fat may reflect adiposity better than BMI and this may explain some of our findings. For example, higher waist circumference has been associated with insulin resistance and higher levels of IGF-I compared to general obesity, which is linked to higher levels of estrogens among postmenopausal women [9]. It is possible that central and general obesity 
Table 7 Association of body size with postmenopausal breast cancer by hormone receptor status

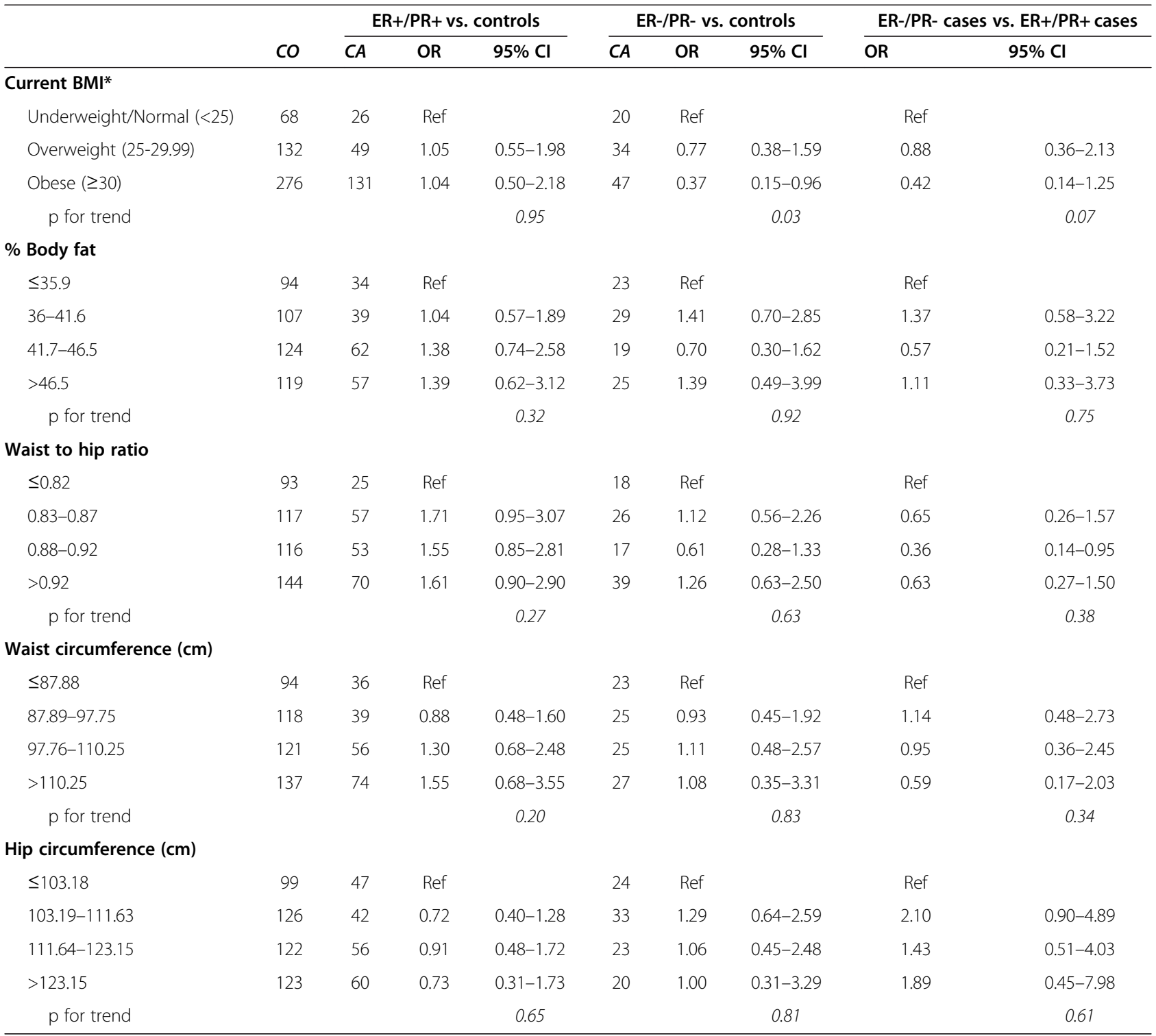

*BMI measured at interview.

Abbreviations: $\mathrm{CO}$ number of controls, CA number of cases, ER estrogen receptor, PR progesterone receptor.

Adjusted for age, ethnicity, country of origin (United States, Caribbean, other), education, family history of breast cancer, history of benign breast disease,

age at menarche, age at menopause (for postmenopausal women), parity (continuous), breastfeeding (yes/no), age at first birth, HRT use (ever/never), OC use (ever/never). BMI also adjusted for waist circumference. Percent body fat, waist circumference, and hip circumference, also adjusted for BMI. For postmenopausal women, percent body fat adjusted for years since menopause instead of age at menopause.

play different roles in AA and EA because the relative role of hormonal pathways may be different in the two groups. For example, consistent with other studies, the Multi-Ethnic Cohort Study found lower postmenopausal breast cancer rates in AA compared to white women, but endogenous estrogen levels were found to be significantly higher among AA, suggesting that estrogens may play a less significant role on breast cancer etiology among them [34]. Furthermore, a cross-sectional study among AA pre-menopausal women found that upper body fat distribution (WHR >0.8) was a better marker for a high risk hormonal profile (high estrogens, androgens, and prolactin, and low sex hormone binding globulin) for breast cancer than general obesity [35].

Case-control studies are subjected to well-known limitations such as recall bias and selection bias. It is well known that women tend to underestimate weight and overestimate height, which could affect BMI computation. However, for the main variables under investigation we did not rely on participants' recall and, instead, objective body measurements were taken. Case-control studies are also prone to selection bias if the participating 
controls are not representative of the source population that gave rise to cases. To improve participation among AA controls, we supplemented RDD recruitment for AA women in NJ with community recruitment. Communitybased recruitment was efficient in recruiting participants and even some cases and RDD controls who refused to participate in our study when they were first approached, called us to do it after they saw the study advertised in their communities (e.g., churches). This gave us some reassurance that the three groups (cases, RDD controls, and community controls) came from the same source population [11]. Another limitation in our study is that we did not have information on obesity-related comorbidities and, therefore, we were not able to adjust for them. To some extent, this may have explained the association found with abdominal obesity in premenopausal women.

\section{Conclusions}

Our study contributes to the limited literature on BMI and other measures of adiposity and breast cancer risk in AA women. As more evidence accumulates on the relationship between BMI and breast cancer, it is becoming obvious that the association is not straightforward, with obesity affecting differently the various subgroups defined by age, race/ethnicity, hormone receptor status, and use of exogenous hormones. For AA women, the evidence remains scarce, but points to a different relationship from that reported in EA, suggesting possible different mechanisms. Larger studies in AA women are needed to further evaluate these issues, as well as evaluate the effect by "intrinsic" subtypes (luminal A, luminal $B$, basal-like and human epidermal growth factor receptor 2-positive/estrogen receptor-negative), which were suggested in one study to be affected differently by adiposity measures [36]. Future research is also needed to address the possibility that obesity affects breast cancer risk through its contribution to obesity-related comorbidities, including diabetes, which are more common among AA breast cancer patients, possibly through overlapping biologic mechanisms underlying associations between obesity, comorbidities, and breast cancer risk.

In summary, we found that higher waist and hip circumference were associated with increased risk of premenopausal breast cancer. While we did not find increased risk for general obesity, other studies have found that a higher BMI is associated with more advanced disease at diagnosis [37-39]. Therefore, maintenance of a healthy weight should be a goal for all women, but particularly for AA women. By doing so, they could improve their chances of survival if they develop breast cancer, as well as prevent other chronic diseases highly prevalent in this population, such as type II diabetes and cardiovascular disease [40].

\section{Abbreviations}

AA: African ancestry; EA: European ancestry; NYC: New York City; NJ: New Jersey; RDD: Random digit dialing; SD: Standard deviation; OR: Odds ratio; Cl: Confidence interval; BMI: Body mass index; WHR: Waist-to-hip ratio; HRT: Hormone replacement therapy; OC: Oral contraceptives; ER: estrogen receptor; PR: Progesterone receptor; NHANES: National Health and Nutrition Examination Survey; WCHS: Women's Circle of Health Study; NJSCR: New Jersey State Cancer Registry.

\section{Competing interests}

The authors declare that they have no competing interests.

\section{Authors' contributions}

EVB and CBA designed the study. EVB, CBA, GC directed its implementation. EVB and UC designed the analytic strategy. UC and GZ conducted data processing and cleaning. UC conducted statistical analyses. SEM and CCH provided expertise in the interpretation of results. EVB wrote the first draft of the manuscript and all co-authors provided substantive comments and editorial review and approved the final version of the manuscript.

\section{Acknowledgments}

This work was supported in part by grants from the US National Institutes of Health (P01 CA151135, R01 CA100598, K22 CA138563, and P30CA072720), US Army Medical Research and Material Command (DAMD-17-01-1-0334), the Breast Cancer Research Foundation, and a gift from the Philip L. Hubbell family. The New Jersey State Cancer Registry is supported by the National Program of Cancer Registries of the Centers for Disease Control and Prevention under cooperative agreement 1US58DP003931-01 awarded to the New Jersey Department of Health. The collection of New Jersey cancer incidence data is also supported by the Surveillance, Epidemiology, and End Results program of the National Cancer Institute under contract N01-PC-2010-0027 and the State of New Jersey. The authors thank Dr. Dana Bovbjerg, Ms. Lina Jandorf, and Ms. Edie Prescod for their contribution to the Women's Circle of Health Study. We also thank our research personnel at the Cancer Institute of New Jersey (now Rutgers Cancer Institute of New Jersey), Roswell Park Cancer Institute, Mount Sinai School of Medicine (now Icahn School of Medicine at Mount Sinai), UMDNJ School of Public Health (now Rutgers School of Public Health), and the New Jersey State Cancer Registry, as well as our African American breast cancer advocates and community partners, and all the women who generously donated their time to participate in the study.

\section{Author details}

${ }^{1}$ Rutgers Cancer Institute of New Jersey, Robert Wood Johnson Medical School, 195 Little Albany Street, 08903 New Brunswick, NJ, USA. ${ }^{2}$ Rutgers School of Public Health, Piscataway, NJ, USA. ${ }^{3}$ Department of Cancer Prevention \& Control, Roswell Park Cancer Institute, Buffalo, NY, USA. ${ }^{4} \mathrm{New}$ Jersey State Cancer Registry, New Jersey Department of Health, Trenton, NJ, USA.

Received: 26 February 2013 Accepted: 12 October 2013

Published: 14 October 2013

\section{References}

1. DeSantis C, Siegel R, Bandi P, Jemal A: Breast cancer statistics, 2011. CA Cancer J Clin 2011, 61(6):409-418.

2. Maskarinec G, Sen C, Koga K, Conroy SM: Ethnic differences in breast cancer survival: status and determinants. Womens Health (Lond Engl) 2011, 7(6):677-687.

3. Stephenson GD, Rose DP: Breast cancer and obesity: an update. Nutr Cancer 2003, 45(1):1-16.

4. Rose DP, Haffner SM, Baillargeon J: Adiposity, the metabolic syndrome, and breast cancer in African-American and white American women. Endocr Rev 2007, 28(7):763-777.

5. Flegal KM, Carroll MD, Kit BK, Ogden CL: Prevalence of obesity and trends in the distribution of body mass index among US adults, 1999-2010. JAMA 2012, 307(5):491-497.

6. World Cancer Research Fund International/American Institute for Cancer Research: Continuous Update Project Report Summary: food, nutrition, physical activity, and the prevention of breast cancer; 2010. http://www.dietandcance rreport.org/cancer_resource_center/downloads/cu/Breast-Cancer-2010Report.pdf. 
7. Chandran U, Hirshfield KM, Bandera EV: The role of anthropometric and nutritional factors on breast cancer risk in African-American women. Public Health Nutr 2012, 15(4):738-748

8. Sexton KR, Franzini L, Day RS, Brewster A, Vernon SW, Bondy ML: A review of body size and breast cancer risk in Hispanic and African American women. Cancer 2011, 117(23):5271-5281.

9. Harvie M, Hooper L, Howell AH: Central obesity and breast cancer risk: a systematic review. Obes Rev 2003, 4(3):157-173.

10. Ambrosone CB, Ciupak GL, Bandera EV, Jandorf L, Bovbjerg DH, Zirpoli G, Pawlish K, Godbold J, Furberg H, Fatone A, et al: Conducting molecular epidemiological research in the Age of HIPAA: a multi-institutional case-control study of breast cancer in African-American and European-American women. J Oncol 2009, 2009:871250.

11. Bandera EV, Chandran U, Zirpoli G, McCann SE, Ciupak G, Ambrosone CB: Rethinking sources of representative controls for the conduct of casecontrol studies in minority populations. BMC Med Res Methodol 2013, 13:71.

12. Swanson CA, Coates RJ, Schoenberg JB, Malone KE, Gammon MD, Stanford $J$, Shorr IJ, Potischman NA, Brinton LA: Body size and breast cancer risk among women under age 45 years. Am J Epidemiol 1996, 143(7):698-706.

13. Verweij LM, Terwee CB, Proper KI, Hulshof CT, Van Mechelen W: Measurement error of waist circumference: gaps in knowledge. Public Health Nutr 2012, 16(2):281-288.

14. Van den Brandt PA, Spiegelman D, Yaun SS, Adami HO, Beeson L, Folsom AR Fraser G, Goldbohm RA, Graham S, Kushi L, et al: Pooled analysis of prospective cohort studies on height, weight, and breast cancer risk. Am J Epidemiol 2000, 152(6):514-527.

15. Morimoto LM, White E, Chen Z, Chlebowski RT, Hays J, Kuller L, Lopez AM, Manson J, Margolis KL, Muti PC, et al: Obesity, body size, and risk of postmenopausal breast cancer: the Women's health initiative (United States). Cancer Causes Control 2002, 13(8):741-751.

16. Adams-Campbell LL, Kim KS, Dunston G, Laing AE, Bonney G, Demenais F: The relationship of body mass index to reproductive factors in pre- and postmenopausal African-American women with and without breast cancer. Obes Res 1996, 4(5):451-456

17. Schatzkin A, Palmer JR, Rosenberg L, Helmrich SP, Miller DR, Kaufman DW, Lesko SM, Shapiro S: Risk factors for breast cancer in black women. J Natl Cancer Inst 1987, 78(2):213-217.

18. Hall IJ, Newman B, Millikan RC, Moorman PG: Body size and breast cancer risk in black women and white women: the Carolina breast cancer study. Am J Epidemiol 2000, 151(8):754-764.

19. Zhu K, Caulfield J, Hunter S, Roland CL, Payne-Wilks K, Texter L: Body mass index and breast cancer risk in African American women. Ann Epidemiol 2005, 15(2):123-128.

20. John EM, Sangaramoorthy M, Phipps Al, Koo J, Horn-Ross PL: Adult body size, hormone receptor status, and premenopausal breast cancer risk in a multiethnic population: the San Francisco Bay area breast cancer study. Am J Epidemiol 2011, 173(2):201-216.

21. Berstad P, Coates RJ, Bernstein L, Folger SG, Malone KE, Marchbanks PA, Weiss LK, Liff JM, McDonald JA, Strom BL, et al: A case-control study of body mass index and breast cancer risk in white and African-American women. Cancer Epidemiol Biomarkers Prev 2010, 19(6):1532-1544.

22. Palmer JR, Adams-Campbell LL, Boggs DA, Wise LA, Rosenberg L: A prospective study of body size and breast cancer in black women. Cancer Epidemiol Biomarkers Prev 2007, 16(9):1795-1802.

23. Mayberry RM: Age-specific patterns of association between breast cancer and risk factors in black women, ages 20 to 39 and 40 to 54 . Ann Epidemiol 1994, 4(3):205-213.

24. Brinton LA, Benichou J, Gammon MD, Brogan DR, Coates R, Schoenberg JB: Ethnicity and variation in breast cancer incidence. Int J Cancer 1997, 73(3):349-355.

25. White KK, Park SY, Kolonel LN, Henderson BE, Wilkens LR: Body size and breast cancer risk: the multiethnic cohort. Int J Cancer 2012, 131(5):E705-E716.

26. Adebamowo CA, Ogundiran TO, Adenipekun AA, Oyesegun RA, Campbell OB, Akang EU, Rotimi CN, Olopade Ol: Obesity and height in urban Nigerian women with breast cancer. Ann Epidemiol 2003, 13(6):455-461.

27. Nemesure B, Wu SY, Hennis A, Leske MC: Body size and breast cancer in a black population-the Barbados national cancer study. Cancer Causes Control 2009, 20(3):387-394.

28. Ogundiran TO, Huo D, Adenipekun A, Campbell O, Oyesegun R, Akang E, Adebamowo C, Olopade Ol: Body fat distribution and breast cancer risk: findings from the Nigerian breast cancer study. Cancer Causes Control 2012, 23(4):565-574.
29. Kleinbaum DG, Kupper LL, Muller KE: Applied regression analysis and other multivariable methods. 2nd edition. Boston: PWS-Kent Publishing Company; 1988

30. Allison PD: Logistic regression using SAS: theory and application. 2nd edition Cary, NC, USA: SAS Institute Inc; 2012

31. Willett W: Nutritional epidemiology. 3rd edition. Oxford: Oxford University Press; 2013.

32. Sheean PM, Hoskins K, Stolley M: Body composition changes in females treated for breast cancer: a review of the evidence. Breast Cancer Res Treat 2012, 135(3):663-680.

33. Flegal KM, Shepherd JA, Looker AC, Graubard BI, Borrud LG, Ogden CL, Harris TB, Everhart JE, Schenker N: Comparisons of percentage body fat, body mass index, waist circumference, and waist-stature ratio in adults. Am J Clin Nutr 2009, 89(2):500-508.

34. Setiawan WW, Haiman CA, Stanczyk FZ, Le Marchand L, Henderson BE: Racial/ethnic differences in postmenopausal endogenous hormones: the multiethnic cohort study. Cancer Epidemiol Biomarkers Prev 2006, 15(10):1849-1855.

35. Barnett JB, Woods MN, Rosner B, McCormack C, Longcope C, Houser RF Jr, Gorbach SL: Sex hormone levels in premenopausal African-American women with upper and lower body fat phenotypes. Nutr Cancer 2001 41(1-2):47-56.

36. Millikan RC, Newman B, Tse CK, Moorman PG, Conway K, Dressler LG, Smith LV, Labbok MH, Geradts J, Bensen JT, et al: Epidemiology of basal-like breast cancer. Breast Cancer Res Treat 2008, 109(1):123-139.

37. Jones BA, Kasi SV, Curnen MG, Owens PH, Dubrow R: Severe obesity as an explanatory factor for the black/white difference in stage at diagnosis of breast cancer. Am J Epidemiol 1997, 146(5):394-404.

38. Deglise C, Bouchardy C, Burri M, Usel M, Neyroud-Caspar I, Vlastos G, Chappuis PO, Ceschi M, Ess S, Castiglione M, et al: Impact of obesity on diagnosis and treatment of breast cancer. Breast Cancer Res Treat 2010, 120(1):185-193.

39. Stark A, Stahl MS, Kirchner HL, Krum S, Prichard J, Evans J: Body mass index at the time of diagnosis and the risk of advanced stages and poorly differentiated cancers of the breast: findings from a case-series study. Int J Obes 2010, 34(9):1381-1386.

40. Ten leading causes of death for African Americans. http://www.cdc.gov/ minorityhealth/populations/REMP/black.html.

doi:10.1186/1471-2407-13-475

Cite this article as: Bandera et al.: Body fatness and breast cancer risk in women of African ancestry. BMC Cancer 2013 13:475.

\section{Submit your next manuscript to BioMed Central and take full advantage of:}

- Convenient online submission

- Thorough peer review

- No space constraints or color figure charges

- Immediate publication on acceptance

- Inclusion in PubMed, CAS, Scopus and Google Scholar

- Research which is freely available for redistribution 